\title{
Presentation of ischemic heart disease cases in tertiary care centres located in central India
}

\author{
Prakash Nayak 0. ${ }^{{ }^{*}}$ \\ DOI: https://doi.org/10.17511/ijmrr.2019.i05.12
}

1* Om Prakash Nayak, Associate Professor, Department of Medicine, Chirayu Medical College \& Hospital, Bhopal, Madhya Pradesh, India.

Background: Cardiovascular disease, one of the non-communicable diseases, has become a major public health problem in many developing countries. There is an epidemiological transition from infective/ communicable disease to Non communicable/degenerative diseases, increases in the prevalence of cardiovascular risk factors, and ageing of the population, which eventually leads to an increase in the absolute numbers of people with coronary heart disease (CHD) especially ischemic heart disease. This will need an increase demand of health awareness and demand for health care facilities. Aim: To know different ways of presentation of IHD cases. Material \& Method: In this study total 255 IHD cases aged between 21 to 90 years were assessed between April 2017 to March 2018. Study was conducted in tertiary care centre located I central India. Informed consent was taken from patients or their relatives in case of unconsciousness of patient. Result: Total 255 patients were enrolled in this study out of which 175 were male with mean age of $58.57 \pm 7.2$ years and 80 female patients were enrolled with mean age of $63.14 \pm 4.6$ years. 18 patients were died. Most of the patients (59.22\%) were mainly came with complain of chest pain. Other patients were coming with complain of breathlessness (7.06\%), nausea/ vomiting (8.24\%) and uneasiness $(8.23 \%)$. Conclusion: over the time after independence trends and presentation of cardiovascular diseases especially ischemic heart disease is change. Knowing of current way of presentation is important. As disease trend is changing, knowledge of their pattern and availability of health resources accordingly is must.

Keywords: Cardiovascular disease, Ischemic heart disease, Coronary artery disease, Chest pain

Corresponding Author

Om Prakash Nayak, Associate Professor, Department of Medicine, Chirayu Medical College \& Hospital, Bhopal, Madhya Pradesh, India.

Email: dropnayak1963@gmail.com
How to Cite this Article

Nayak OP. Presentation of ischemic heart disease cases in tertiary care centres located in central India. Int J Med Res Rev. 2019;7(5):430-436.

Available From

https://ijmrr.medresearch.in/index.php/ijmrr/article/ view/1091
To Browse

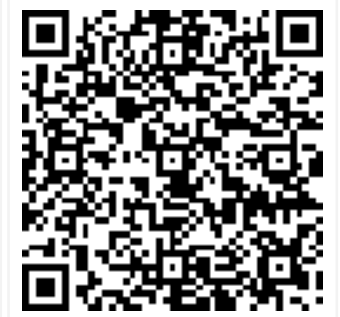

Manuscript Received 2019-09-04

Conflict of Interest No

Review Round 1
2019-09-14
Funding
Nil

$\begin{gathered}\text { Review Round } 2 \\ \text { 2019-09-19 }\end{gathered}$
Ethical Approval
Yes

Review Round 2

Yes
Review Round 3

Plagiarism X-checker $6 \%$
Accepted 2019-09-23

Note

(C) 2019 by Om Prakash Nayak and Published by Siddharth Health Research and Social Welfare Society. This is an Open Access article licensed under a Creative Commons Attribution 4.0 International Licens
unported [CC BY 4.0]. 


\section{Introduction}

Over the last seventy there is change in disease pattern in south east asian region. Ischemic heart disease (IHD) represents the leading cause of death in elderly [1]. Ischaemia means a reduced blood supply. The coronary arteries supply blood to the heart muscle and no alternative blood supply exists, so a blockage in the coronary arteries reduces the supply of blood to heart muscle. Most ischaemic heart disease is caused by atherosclerosis, usually present even when the artery lumens appear normal by angiography [2-4].

The presentation of ischemic heart disease varied from site to site and continent to continent. Presentation is different in male and females this is because of some biological factors, social, environmental, and community factors [5]. Mortality because of ischemic heart disease is increases with day passes. This was mainly because of unavailability of health facilities at rural levels and urban slums, Mode of transportation and communication is less and population explosion [48].An expanded view of the multifactorial epidemiology of IHD has identified important risk factors, including age, race, culture, ethnicity, and lifestyle influences that adversely impact cardiovascular outcomes.

Hypertension, diabetes mellitus, and smoking are more potent risk factors for MI in all age group. Key contributory factors to progression of atheromatous disease include smoking, hypertension, hyperlipidaemia, diabetes, and obesity [7-9]. Chest discomfort in the setting of exertion or emotional stress is the predominant clinical presentation of chronic stable angina. The typical presentation is exertional, or stress induced central chest pain. These episodes usually last from a few minutes to hours and can resolve upon rest. Common descriptions by the patient include tightness, crushing stabbing or burning pain. Patients may also have nausea and vomiting, dyspnoea, palpitations [10].

Typical symptoms increase the likelihood of an acute myocardial infarction (AMI) however atypical presentations cannot be used to exclude AMI. Women, the elderly and those with diabetes mellitus often present with atypical chest pain. Atypical presentations, including pain in the epigastrium, jaw, neck, or arms are also common, particularly in women, people with diabetes, and older people.
Although the ECG is relatively insensitive, the presence of ST segment elevation however is $100 \%$ diagnostic for AMI and serves as the criterion for immediate induction of fibrinolytic therapy or emergency interventional revascularization [9-12].

In acute MI condition time to reach to health facility is also important and many studies showed that each minute is important. With this background this study was planned to know the presentation of ischemic heart disease cases in tertiary care centres and what are the different ways of their presentation.

\section{Methodology}

Setting: This study was conducted on tertiary care centre located in Bhopal city.

Study Duration: The study duration was April 2017 to March 2018.

Type of Study: Cross sectional Study

Sampling method: All the cases coming to medicine OPD during the study period suspecting symptoms of Ischemic Heart disease that include both based of history or with atypical symptoms but having characteristic changes in Electrocardiography were included in the study.

Sample size calculation: This study included all the cases came during the study duration. In this duration total 295 cases reported at the centre out of which 40 were excluded based on exclusion criteria. Sample size of study was 255 between age group of 21 to 90 years.

Data collection procedure: Patients details along with clinical history was recorded in predesigned semi-structed questionnaire. This data collection tool included their demographic data, Signs and symptoms, past and family history.

Data analysis plan: Data was entered in Microsoft office excel and analysed.

Ethical consideration and permission: This study was approved by institutional ethical committee and informed consent was obtained from all participants.

\section{Result}

In this study total 255 cases came in medicine department OPD and Emergency during the study period with ischemic heart disease. 
The patients were from age of 21 to 90 years. Most of patients were belong to age group of 51 to 60 years $(32.5 \%)$ and 61 to 70 years $(27.8 \%$ ) (Table $1)$. The mean age of participants was $59.43 \pm 5.3$ years. When differentiated in male and females, mean age of male patients was $58.57 \pm 7.2$ and female patients was $63.14 \pm 4.6$ years. Among all the patients 175 were male and 80 were females. Total $18(7.05 \%)$ patients were died. Out of these 18 died patients, 12 were male and 6 were female (Figure $1)$.

Table-1: Distribution of Cases according to age Group

\begin{tabular}{|l|l|l|}
\hline \multicolumn{1}{|c|}{ Age Group } & \multicolumn{1}{c|}{ Number } & \multicolumn{2}{c|}{ Percentage } \\
\hline $21-30$ & 5 & 2.0 \\
\hline $31-40$ & 10 & 4.0 \\
\hline $41-50$ & 34 & 13.3 \\
\hline $51-60$ & 83 & 32.5 \\
\hline $61-70$ & 71 & 27.8 \\
\hline $71-80$ & 39 & 15.3 \\
\hline $81-90$ & 13 & 5.1 \\
\hline Total & 255 & 100 \\
\hline
\end{tabular}

\begin{tabular}{|c|c|c|}
\hline 200 & & \\
\hline 180 & & \\
\hline 160 & 12 & \\
\hline 140 & & \\
\hline 120 & & \\
\hline 100 & & \\
\hline 80 & 163 & \\
\hline 60 & & \\
\hline 40 & & 74 \\
\hline 20 & & \\
\hline 0 & Male & Female \\
\hline & & \\
\hline
\end{tabular}

Figure- 1: Deaths in a different sex distribution.

Table-2: Distribution of Cases according Presenting Symptoms

\begin{tabular}{|l|l|l|}
\hline \multicolumn{1}{|c|}{ Presenting Symptoms } & No. of Cases & Percentage \\
\hline Chest Pain & 151 & 59.22 \\
\hline Palpitation & 6 & 2.35 \\
\hline Breathlessness & 18 & 7.06 \\
\hline Perspiration & 13 & 5.10 \\
\hline Nausea/ vomiting & 21 & 8.24 \\
\hline Cough & 5 & 1.96 \\
\hline Fever & 3 & 1.18 \\
\hline Abnormal Behaviour & 1 & 0.39 \\
\hline Uneasiness & 21 & 8.23 \\
\hline Shock & 4 & 1.56 \\
\hline Drowsy & 2 & 0.78 \\
\hline Vertigo & 3 & 1.18 \\
\hline
\end{tabular}

\begin{tabular}{|l|l|l|}
\hline Unconsciousness & 3 & 1.18 \\
\hline Loose Motion & 1 & 0.39 \\
\hline Asymptomatic (Silent) & 3 & 1.18 \\
\hline
\end{tabular}

Table-3: Time interval between onset of symptoms and arrival to the hospital.

\begin{tabular}{|l|l|l|}
\hline \multicolumn{1}{|c|}{ Time Interval } & No. of Cases & Percentage \\
\hline Within 1 Hour & 31 & 12.15 \\
\hline 1 hour to Less than 6 hours & 64 & 25.10 \\
\hline 6 Hour to less than 24 hours & 128 & 50.20 \\
\hline After 24 Hours & 32 & 12.55 \\
\hline
\end{tabular}

Table-4: Different sites of radiation pain.

\begin{tabular}{|l|l|l|}
\hline \multicolumn{1}{|c|}{ Radiation Sites } & \multicolumn{1}{c|}{ No. of Cases } & \multicolumn{1}{c|}{ Percentage } \\
\hline Neck \& Jaw & 28 & 10.98 \\
\hline Left Arm & 34 & 13.33 \\
\hline Epigastric Pain & 11 & 4.31 \\
\hline Both Arms & 17 & 6.66 \\
\hline Back & 10 & 3.92 \\
\hline None & 155 & 60.78 \\
\hline
\end{tabular}

Table-5: Past history, personal and family history related to IHD.

\begin{tabular}{|l|l|l|}
\hline \multicolumn{1}{|c|}{ Past History } & \multicolumn{1}{c|}{ No. of Cases } & Percentage \\
\hline Hypertension & 150 & 58.82 \\
\hline Diabetes & 99 & 38.82 \\
\hline Ischemic heart disease & 96 & 37.64 \\
\hline Chronic kidney disease & 2 & 0.78 \\
\hline Stroke & 2 & 0.78 \\
\hline No Past History & 37 & 14.50 \\
\hline Family History & \multicolumn{2}{|l|}{} \\
\hline Hypertension & 73 & 28.62 \\
\hline Diabetes & 19 & 7.45 \\
\hline Ischemic heart disease & 19 & 7.45 \\
\hline No family history & 115 & 60.78 \\
\hline Personal History & \multicolumn{2}{|l}{} \\
\hline Veg diet & 102 & 40.00 \\
\hline Non-veg diet & 153 & 60.00 \\
\hline Smoking & 117 & 45.88 \\
\hline Alcohol & 97 & 38.04 \\
\hline Tobacco chewing & 17 & 6.66 \\
\hline
\end{tabular}

Most of the patients (59.22\%) were mainly came with complain of chest pain. Other patients were coming with complain of breathlessness (7.06\%), nausea/ vomiting (8.24\%) and uneasiness (8.23\%) (Table 2). Time interval between onset of symptoms and arrival to hospital is very important. Only 31 patients $(12.15 \%)$ came within one hour of onset of symptoms. 64 and 128 patients were coming between 1 to 6 hour and 6 hours to 24 hours respectively (Table 3 ). There were 100 patients who had radiation pain. 
This pain is mainly radiating toward Neck and jaw in $10.98 \%$ patients, Left arm in $13.33 \%$ patients and $6.66 \%$ in Epigastric area. (Table 4).

There were 150 patients (58.82\%) had past history of hypertension, 99 (38.82\%) had diabetes and 96 (37.64\%) patients had history of ischemic heart disease. The family history is also an important factor for diagnosis. In this study 73 patients $(28.62 \%)$ had family history of hypertension, 19 $(7.45 \%)$ diabetes and $19(7.45 \%)$ had family history of ischemic heart disease. But 115 (60.78\%) patients did not have any family history. There were 102 patients had vegetarian diet and 153 patients were on non-vegetarian diet. 117 patients (45.88\%) were had history of smoking and 97 patients (38.04\%) had history of Alcohol intake (Table 5).

\section{Discussion}

Epidemiological studies revealed that incidence and prevalence of Ischemic heart disease is increasing day by day and increase trend is seen in risk factor of these diseases. This study had a total of 255 patients with 170 male and 80 females. This study showed that $60.3 \%$ were in the age group of 51 to 70 years. Indians have one of the highest rates of heart disease in the world.

The disease also tends to be more aggressive and manifests at a younger age. 18 patients came to institute were died [13]. Women suffering from acute coronary syndrome or myocardial infarction are likely to be older: are more likely to have a history of hypertension, diabetes, unstable angina, hyperlipidemia, and congestive heart failure; and are less likely to be smokers than their somewhat higher than male counterpart [14-17].

Out of these 18 , about 10 had complain of chest pain and rest 8 were without complain of chest pain they only complain of breathlessness and uneasiness. This finding is quite consistent with finding of other study stated that patients who experienced MI with chest pain had less likely to die than compared with patients with chest pain [18].

The main reason behind that was delay in seeking care and delay in receiving important therapy. In the present study chest pain was the most common presenting complaint followed by sweating and breathlessness. Presenting symptoms usually include chest pain with typical radiation, nausea and diaphoresis. Older patients less frequently have typical signs and symptoms such as chest pain with classical radiation pattern.
In the present study some patients did not present with the chest pain, among which many were having diabetes mellitus.

Diabetic patients are likely to present with the atypical symptoms. Similar finding was found in many other studies [19-23]. This study showed that $58.82 \%$ had hypertension and $38.82 \%$ had diabetes. Similar finding was observed in Study of Kumar $\mathrm{N}$ et al where $40.40 \%$ were diabetic and $45.72 \%$ were hypertensive. Some studies said that diabetes was a important risk factor for a typical presentation.

Some other risk factors for atypical presentation are older age group female sex and past past history of congestive heart failure [24-25.] This study was conducted in tertiary care center located in one of the largest city of central India and many cases of adjacent part came to this hospital at the late stage so it might be the case that this study showed large mortality and complications. This study also gave some recommen-dations to give special focus on non communicable disease whose incidence and prevalence is increasing day by day.

\section{Conclusion}

IHD is one of the most important causes of mortality and morbidity in the India. It also leads to massive economic burden. Modern lifestyle is a causative factor for non-communicable diseases. The findings of this study indicate that the trends, incidence and prevalence of coronary artery disease and coronary risk factors is increasing in urban and rural population in India. Some more research is required to assess the impact of physical activity, dietary habit changes and reduced use of poly unsaturated fatty acid, no smoking, and controlling blood pressure and cholesterol. It was always said that prevention is better than cure so in case of IHD is very much true. Assessment of different pattern of presentation of IHD cases is important for early identification of cases.

\section{What the study adds to the existing knowledge?}

The present study is indicative of the fact about the increasing trends in cases of IHD in central India, which further establishes the necessity of planning a more in-depth research studies required to assess the role of various other factors for identification of IHD cases. 
Acknowledgement: Author would like to thank to all staff working in my department for helping me in conduction of this study and also supporting me in each and every step.

\section{Reference}

01. Begom R, Singh RB. Prevalence of coronary artery disease and its risk factors in the urban population of South and North India. Acta Cardiol. 1995;50(3)227-240.

[Crossref]

02. Gupta R, Gupta VP. Meta-analysis of coronary heart disease prevalence in India. Indian Heart J. $1996 ; 48(3) 241-245$.

[Crossref]

03. Kutty VR, Balakrishnan KG, Jayasree AK, Thomas J. Prevalence of coronary heart disease in the rural population of Thiruvananthapuram district, Kerala, India. Int J Cardiol. 1993;39(1)59-70.

doi: 10.1016/0167-5273(93)90297-t [Crossref]

04. Gupta R, Prakash H, Majumdar S, Sharma S, Gupta VP. Prevalence of coronary heart disease and coronary risk factors in an urban population of Rajasthan. Indian Heart J. 1995;47(4)331-8. [Crossref]

05. Singh RB, Niaz MA, Ghosh S, Beegom R, Chibo $H$, Agarwal $P$, et al. Epidemiological study of coronary artery disease and its risk factors in an elderly urban population of north India. J Am Coll Nutr. 1995;14(6)628-634.

doi: 10.1080/07315724.1995.10718552 [Crossref]

06. Gupta SP, Malhotra KC. Urban--rural trends in the epidemiology of coronary heart disease. J Assoc Physicians India. 1975;23(12)885-892.

[Crossref]

07. Janus ED, Postiglione A, Singh RB, Lewis B. The modernization of Asia, Implications for coronary heart disease, Council on Arteriosclerosis of the International Society and Federation of Cardiology. Circulation. 1996;94(11)2671-2673. doi: 10.1161/01.cir.94.11.2671 [Crossref]

08. Chadha SL, Radhakrishnan S, Ramachandran K, Kaul U, Gopinath N. Epidemiological study of coronary heart disease in urban population of Delhi. Indian J Med Res. 1990;92;424-430.

[Crossref]
09. Singh RB, Sharma JP, Rastogi V, Raghuvanshi RS, Moshiri M, Verma SP, et al. Prevalence of coronary artery disease and coronary risk factors in rural and urban populations of north India. Eur Heart J. 1997;18(11)1728-1735.

doi: $\quad$ 10.1093/oxfordjournals.eurheartj.a015167 [Crossref]

10. Mohan V, Deepa R, Rani SS, Premalatha G. Chennai Urban Population Study (CUPS No-5), Prevalence of coronary artery disease and its relationship to lipids in a selected population in South India- The Chennai Urban Population Study (CUPS No-5). J Am Coll Cardiol. $2001 ; 38(3) 682-687$.

doi: 10.1016/s0735-1097(01)01415-2 [Crossref]

11. Gupta R, Gupta VP, Sarna M, Bhatnagar S, Thanvi J, Sharma V, et al. Prevalence of coronary heart disease and risk factors in an urban Indian population- Jaipur Heart Watch-2. Indian Heart J. 2002;54(1)59-66.

[Crossref]

12. Latheef SA, Subramanyam G. Prevalence of coronary artery disease and coronary risk factors in an urban population of Tirupati. Indian Heart J. 2007;59(2)157-164.

[Crossref]

13. Enas EA, Yusuf S, Mehta JL. Meeting of the International Working Group on Coronary Artery Disease in South Asians. Indian Heart J. $1996 ; 48 ; 727-732$.

[Crossref]

14. Kumar N, Sharma S, Mohan B, Beri A, Aslam N, Sood $N$, et al. Clinical and angiographic profile of patients presenting with first acute myocardial infarction in a tertiary care center in northern India. Indian Heart J. 2008;60(3)210214.

[Crossref]

15. DeVon HA, Zerwic JJ. Symptoms of acute coronary syndromes are there gender differences?- A review of the literature. Heart Lung. 2002;31(4)235-245. doi: $10.1067 / \mathrm{mhl} .2002 .126105$ [Crossref]

16. Hochman JS, Tamis-Holland JE. Acute coronary syndromes- does sex matter?. Jama. 2002;288(24)3161-3164.

doi: $10.1001 /$ jama.288.24.3161 [Crossref] 
17. Collins L, Douglas PS. Acute coronary syndromes, In- Douglas PS (ed), Cardiovascular Health \& Disease in Women 2nd ed. Philadelphia- WB Saunders. 2002;316-342. [Crossref]

18. Canto JG, Shlipak MG, Rogers WJ, Malmgren JA, Frederick PD, Lambrew CT, et al. Prevalence, clinical characteristics, and mortality among patients with myocardial infarction presenting without chest pain. JAMA. 2000;283(24)32233229.

doi: 10.1001/jama.283.24.3223 [Crossref]

19. Lokesh S, Shashidhar G. A study of clinical profile of ischemic heart disease among South Indian women in a tertiary care centre. J Evol Med Dent Sci. 2015;4(44)7587-7597. [Crossref]

20. Gupta R, Deedwania PC, Gupta A, Rastogi S, Panwar RB, Kothari K. Prevalence of metabolic syndrome in an Indian urban population. Int J Cardiol. 2004;97(2)257-261.

doi: 10.1016/j.ijcard.2003.11.003 [Crossref]

21. Enas EA, Senthilkumar A, Juturu V, Gupta R. Coronary artery disease in women. Indian Heart J. $2001 ; 53(3) 282-292$.

[Crossref]
22. James C. Risk factors for coronary artery diseases- a study among patients with ischemic heart disease in Kerala. Heart India. 2013; 1(1)7-11. doi: 10.4103/2321-449x.113603 [Crossref]

23. National Cholesterol Education Program (NCEP) Ex-pert Panel on Detection, Evaluation and Treatment of High Blood Cholesterol in Adults (ATP III). Third report of the national cholesterol education program (NCEP) expert panel on detection, evaluation and treatment of high blood cholesterol in adults- Final report. Circulation, 2002;106;3143.

[Crossref]

24. Acharya DU, Shekhar YC, Aggarwal A, Anand IS. Lack of pain during myocardial infarction in diabetics--is autonomic dysfunction responsible?. Am J Cardiol. 1991;68(8)793-796. doi: $\quad 10.1016 / 0002-9149(91) 90657-7 \quad$ [Crossref]

25. Tewari S, Kumar S, Kapoor A, Singh U, Agarwal A, Bharti BB, et al. Premature coronary artery disease in North India- an angiography study of 1971 patients. Indian Heart J. 2005;57(4)311318.

[Crossref] 